\title{
Perilaku Vektor Malaria Anopheles farauti Laveran (Diptera: Culicidae) Di Ekosistem Pantai (Kabupaten Biak Numfor) Dan Ekosistem Rawa (Kabupaten Asmat) Propinsi Papua
}

\author{
Hanna Kawulur ${ }^{1,2}$, RC Hidayat Soesilohadi ${ }^{3}$, Suwarno HadIsusanto ${ }^{4}$, dan Andi Trisyono ${ }^{5}$, \\ ${ }^{1}$ Program Pascasarjana Biologi Universitas Gadjah Mada. Jl. Teknika Selatan, Sekip Utara Yogyakarta. ${ }^{3}$ Fakultas \\ Biologi, Universitas Gadjah Mada. Jl. Teknika Selatan, Sekip Utara, Yogyakarta. ${ }^{3}$ Fakultas Pertanian, Universitas \\ Gadjah Mada. Jl. Teknika Selatan, Sekip Utara, Yogyakarta. \\ ${ }^{2}$ Balai Litbang Biomedis Papua Kementerian Kesehatan RI J1 Kesehatan no 10 Dok 2 Jayapura Kode Pos 99351. \\ Telp./Fax. (0967) 572221. E-mail: hanna22papua@gmail.com.
}

\begin{abstract}
Biak Numfor and Asmat districts reported as malaria endemic areas in Papua (Papua Global Fund, 2011). Anopheles farauti mosquito is one of the malaria vectors in the region. Malaria control efforts have been made but there are still many cases of malaria. Malaria control will provide maximum results if there is a match between the vector behavior and programs undertaken.

The purpose of this study was to determine the bionomics factors (behavioral) of malaria vector An. farauti mosquitoes in coastal ecosystems (Biak Numfor) and swamp (Asmat); namely: (a). density (b) age and (c) bloodseeking behavior. The method used in this study is human landing collection, resting collection and ELISA bloodfeed.

The results showed that the population density of An. farauti mosquito did not have a positive relationship with the number of malaria patients in both study areas. The activity of An. farauti mosquito on blood-seeking at the coastal and swamp ecosystems lasted all night but mainly at 18:00 to 19:00 hour. The study also showed that bloodseeking activity mostly done outside of the house. Age estimation of An. farauti mosquito population at coastal ecosystems ranging from 16-18 days, while in the swamp ecosystem is 12-14 days. Population density, approximately age and blood-seeking behavior indicates that An. farauti mosquitoes on the coastal and swamp ecosystems have the potential to be an effective malaria vector.
\end{abstract}

Keywords: Malaria, Vector, Behavior

\begin{abstract}
Abstrak
Kabupaten Biak Numfor dan Kabupaten Asmat adalah dilaporkan sebagai daerah endemis malaria di Propinsi Papua. (Global Fund Papua, 2011). Nyamuk Anopheles farauti adalah salah satu vektor malaria di wilayah tersebut. Upaya pengendalian malaria telah dilakukan namun kasus malaria masih banyak ditemukan. Pengendalian malaria akan memberikan hasil maksimal jika ada kecocokan antara perilaku vektor dan program yang dilakukan.

Tujuan penelitian ini adalah mengetahui beberapa faktor bionomik (perilaku) nyamuk vektor malaria $A n$. farauti di ekosistem pantai (Kabupaten Biak Numfor) dan ekosistem rawa (Kabupaten Asmat); yaitu: (a). kepadatan (b) umur dan (c) perilaku mencari darah. Metode yang digunakan adalah human landing collection, resting collection dan ELISA pakan darah.

Hasil penelitian menunjukkan bahwa padat populasi nyamuk An. farauti dan tidak memiliki hubungan positif dengan jumlah penderita malaria pada kedua wilayah penelitian. Aktifitas nyamuk An. farauti mencari darah di ekosistem pantai dan rawa berlangsung sepanjang malam namun paling banyak beraktivitas pada pukul 18.00-19.00. Spesies tersebut diketahui lebih banyak melakukan aktifitas mencari darah di luar rumah. Perkiraan umur populasi nyamuk An. farauti di ekosistem pantai berkisar antara 16-18 hari, sedangkan di ekosistem rawa adalah 12-14 hari. Padat populasi, perkiraan umur dan perilaku mencari darah menunjukkan bahwa nyamuk An.farauti di ekosistem pantai dan rawa memiliki potensi menjadi vektor malaria yang efektif.
\end{abstract}

Kata Kunci: Malaria, Vektor, Perilaku 


\section{PENDAHULUAN}

Malaria masih menjadi masalah kesehatan utama di 106 negara hingga tahun 2010, diperkirakan menyerang 216 juta orang serta menyebabkan kematian 655.000 jiwa setiap tahunnya (WHO, 2011). Penyakit ini juga menjadi masalah serius di Indonesia sebab 49,6\% dari total jumlah penduduk, hidup di daerah beresiko terinfeksi malaria Laihad and Gunawan (1999). Tahun 2004 terdapat 424 dari total 579 kabupaten/kota endemik. Pada tahun 2005 jumlah penderita malaria menduduki urutan ke-9 di antara 10 penyakit utama yang dirawat di rumah sakit. Tahun 2010 dilaporkan jumlah kasus malaria klinis mencapai 1.800 .000 jiwa (Kementerian Kesehatan RI, 2011). Kabupaten Biak Numfor dan Asmat dilaporkan sebagai dua daerah di Propinsi Papua yang memiliki kasus malaria tinggi. (Global Fund Papua. 2011).

Upaya pengendalian malaria yang tidak didasari pada pengetahuan tentang faktor perilaku (bionomik) vektor diduga menjadi salah satu penyebab jumlah kasus malaria di daerah penelitian masih tetap tinggi, walaupun berbagai kegiatan penanggulangan telah dilakukan. Kegiatan pengendalian malaria akan memberikan hasil maksimal apabila ada kecocokan antara perilaku vektor dengan metoda yang diterapkan, mengingat wilayah geografis Indonesia luas, kondisi sosial masyarakat berbeda-beda dan bionomik vektor yang beragam. Penelitian ini bertujuan mengetahui beberapa faktor bionomik (perilaku) nyamuk vektor malaria An. farauti di ekosistem pantai (Kabupaten Biak Numfor) dan rawa (Kabupaten Asmat), yaitu: (a) Kepadatan; (b) Umur dan (c) Perilaku mencari darah.

Nyamuk Anopheles termasuk dalam ordo Diptera, famili Culicidae, Sub famili Anophelinae, biasanya hidup didaerah tropis dan sub tropis, tidak ditemukan pada ketinggian di atas 2500 meter dpl (Warrel and Gilles, 2002). Terdapat kurang lebih 60 spesies yang dilaporkan sebagai vektor malaria, dari 400 spesies nyamuk Anopheles yang ada di seluruh dunia (Najera and Zaim, 2003). Di Indonesia dilaporkan ada sekitar 80 spesies Anopheles, dan 22 diantaranya telah terbukti merupakan vektor malaria tersebar di berbagai pulau (Suprapto, 2010). Padat populasi vektor mempengaruhi frekuensi kontak antara manusia dan nyamuk. Makin tinggi populasi Anopheles, secara langsung akan meningkatkan resiko manusia tertular malaria (Taken and Knols, 1990) meskipun tidak selalu berkorelasi dengan kasus penularan tinggi.

Umur nyamuk sangat mempengaruhi endemisitas malaria di suatu daerah. Semakin panjang umur vektor, makin besar peluang spesies tersebut menjadi vektor malaria dan selanjutnya mempengaruhi endemisitas malaria di suatu wilayah. (Dharmawan, 1993) menyatakan bahwa perkiraan umur nyamuk dapat dihitung dengan mengetahui perbandingan antara jumlah nyamuk yang telah bertelur (parous) dan belum pernah bertelur (nulliparous)..

Setiap spesies Anopheles memiliki perilaku yang berbeda dalam menentukan sumber darah untuk kelangsungan hidupnya (sifat antropofilik). Sifat antrophofilik sangat terkait dengan ketersedian sumber darah di sekitar habitatnya. Proporsi nyamuk menghisap darah manusia (Human Blood Index) akan menentukan potensi spesies tersebut sebagai vektor primer atau sekunder di daerah tersebut (Dharmawan, 1993).

Nyamuk dapat juga bersifat heterogen, yaitu tidak selektif dalam memilih hospes sebagai sumber sumber darah. Vektor malaria mampu beradaptasi dan cepat mencari mangsa pengganti bila hospes pilihan tidak dijumpai di lingkungannya (Boewono and Ristiyanto., 2005). Frekuensi menghisap darah nyamuk vektor, terkait dengan siklus gonotropik. Makin pendek siklus gonotropik, makin sering nyamuk tersebut menghisap darah untuk siklus berikutnya, dengan demikian mempunyai potensi lebih besar menjadi vektor yang efisien.

\section{BAHAN DAN METODE}

A. Bahan dan Alat

Bahan yang digunakan untuk koleksi dan identifikasi nyamuk adalah probandus, kapas dibasahi larutan sukrosa 10\%, karet gelang, kain kasa, handuk lembab, silica gel, dan kertas saring. Alat-alat untuk koleksi dan identifikasi nyamuk adalah: aspirator dan senter, paper cup, gunting, tabung ependorf, kotak nyamuk, jarum seksi, slide, 
pinset, pipet pasteur, loupe, dissecting dan compound microscope.

B. Waktu dan tempat

Penelitian di lakukan pada bulan Juni 2011 sampai Januari 2012. Penelitian dlaksanakan di Desa Samber dan Anggopi Kabupaten Biak Numfor (ekosistem pantai) dan Desa Syuru dan Ewer Kabupaten Asmat (ekosistem rawa)

\section{Cara Kerja}

Untuk menghitung kepadatan, mengetahui umur dan sifat antropofilik nyamuk An. faraut, dilakukan penangkapan nyamuk malam hari dengan metode human landing collection dan pembedahan ovarium. Penelitian dilakukan pada pukul 18.00-06.00 di luar dan di dalam rumah selama 40 menit setiap jam. Penangkapan $A n$ farauti istirahat juga dilakukan (resting collection) pada jam 06.00-08.00 di sekitar habitat perkembangbiakan dan di dalam rumah untuk menentukan sumber darah dalam tubuh nyamuk (penentuan sifat antrophofilik vektor) dengan metode ELISA.

Nyamuk yang tertangkap, dibunuh menggunakan kloroform dan diidentifikasi menggunakan mikroskop untuk memastikan spesies yang tertangkap adalah An farauti. Nyamuk An. farauti yang telah diidentifikasi dihitung kepadatannya menggunakan rumus:

MBR $=\frac{\text { jumlah nyamuk yang ditangkap }}{\text { jumlah } \text { penangkap } \mathrm{x} \text { jumlah jam penangkapan }}$

\section{MBR : Man bitting rate}

Saat melakukan penghitungan kepadatan An. farauti, juga dilakukan pengamatan terhadap kebiasaan mencari darah (waktu dan tempat). Nyamuk An farauti dibedah kandung telurnya untuk menghitung proporsi parus dan mendapatkan rentang umur nyamuk, dengan cara: (1) Nyamuk diletakkan di atas slide yang telah ditetesi air; (2) Bagian dada nyamuk ditusuk dengan jarum seksi untuk menahan agar nyamuk tidak bergerak; (3) Kedua sisi ujung ruas perut ke
VII dirobek sedikit; (4) Ujung abdomen (ruas perut terakhir) ditarik perlahan-lahan ke belakang sampai kandung telur keluar; (5) Kandung telur dan sisi perut lainnya diperiksa dengan bantuan mikroskop dengan perbesaran 100x atau 400x; (6) Apabila terlihat ujung tracheola menggulung, berarti nyamuk belum pernah bertelur (nulliparous), sebaliknya bila ujung tracheola membuka/tidak menggulung berarti nyamuk sudah pernah bertelur (parous).

Setelah dilakukan pembedahan, selanjutnya dihitung proporsi parous nyamuk An. farauti untuk mengetahui proporsi populasi nyamuk pernah bertelur dengan cara:

Proporsi parus $=\frac{\text { Jumlahnyamuk An.farauti parus }}{\text { Jumlah nyamuk An.farauti yang diperiksa }}$

\section{HASIL DAN PEMBAHASAN}

\section{A. Kepadatan}

Rata-rata nilai MBR nyamuk An. farauti di ekosistem pantai berkisar antara 20,1-24,3 nyamuk/orang/jam, sedangkan di ekoistem rawa berkisar antara 32,4-39,1 nyamuk/orang/jam (Tabel 1). Data yang diperoleh dari ekosistem pantai dan rawa menunjukkan bahwa padat populasi nyamuk vektor malaria $A n$. farauti di ekosistem rawa relatif lebih tinggi dibandingkan ekosistem pantai. Kondisi tersebut menunjukkan bahwa nyamuk vektor malaria An. farauti di Kabupaten Biak Numfor memiliki peluang lebih kecil mendistribusikan malaria.. Makin tinggi populasi vektor Anopheles, berdampak meningkatkan resiko manusia tertular malaria (Taken and Knols, 1990) meskipun tidak selalu berkorelasi dengan kasus penularan tinggi. Padat populasi vektor mempengaruhi frekuensi kontak antara manusia dan vektor tetapi bukan faktor tunggal penentu kejadian malaria. 
Tabel 1. Nilai MBR Nyamuk An. farauti di Ekosistem Pantai (Kabupaten Biak Numfor) dan Rawa (Kabupaten Asmat) Periode Penangkapan Juni 2011-Januari 2012.

\begin{tabular}{lcc|cc|cc|cc}
\hline \multirow{2}{*}{ Bulan } & \multicolumn{3}{c}{ Ekosistem Pantai } & \multicolumn{3}{c}{ Ekosistem Rawa } \\
\cline { 2 - 9 } & \multicolumn{2}{c}{ Samber } & \multicolumn{2}{c|}{ Anggopi } & \multicolumn{2}{c}{ Syuru } & \multicolumn{2}{c}{ Eewer } \\
\cline { 2 - 9 } & DR & LR & DR & LR & DR & LR & DR & LR \\
\hline Juni & 11,6 & 20,9 & 23,6 & 39,6 & 29,7 & 53,8 & 22,2 & 36,0 \\
Juli & 14,2 & 20,0 & 24,0 & 36,9 & 35,1 & 45,3 & 27,6 & 29,8 \\
Agustus & 11,1 & 16,4 & 22,7 & 32,4 & 35,1 & 47,6 & 22,2 & 28,0 \\
September & 10,2 & 13,3 & 29,8 & 42,7 & 39,1 & 53,8 & 28,0 & 35,6 \\
Oktober & 11,1 & 15,1 & 29,3 & 38,7 & 34,2 & 42,2 & 22,2 & 39,5 \\
November & 12,9 & 13,3 & 27,1 & 44,0 & 31,1 & 44,0 & 22,7 & 37,7 \\
Desember & 12,9 & 9,3 & 30,2 & 44,9 & 35,6 & 53,3 & 23,6 & 34,7 \\
Januari & 14,7 & 10,7 & 27,1 & 28,0 & 42,2 & 39,5 & 26,7 & 33,3 \\
\hline
\end{tabular}

Ket.: DR: dalam rumah; LR: luar rumah.

B. Umur

Hasil penelitian menunjukkan adanya perbedaan proporsi nyamuk parous di ekosistem pantai dan rawa. Proporsi parous nyamuk An. farauti di ekosistem pantai berkisar antara 0,12-0,3 sedangkan di ekosistem rawa 0,13-0,22 . Proporsi parous nyamuk An. farauti di ekosistem pantai relatif lebih rendah dibanding ekosistem rawa, demikian juga dengan jumlah kejadian malaria yang dilaporkan pada dua wilayah tersebut (Gambar 1).

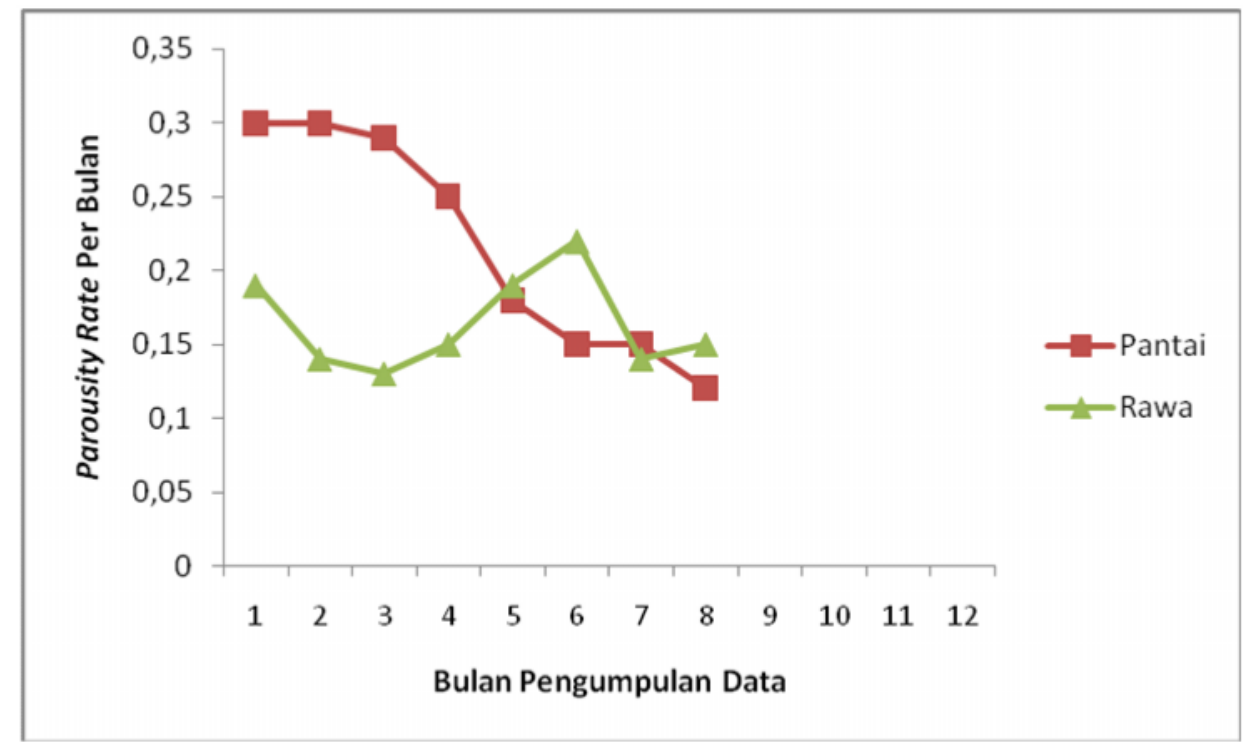

Gambar 1. Proporsi Parous Nyamuk An. farauti di Ekosistem Pantai (Kabupaten Biak Numfor dan Rawa (Kabupaten Asmat).

Proporsi nyamuk bertelur (parous) mempengaruhi nilai harapan hidup dan selanjutnya berdampak pada umur populasi spesies tersebut di alam. (Warrel and Gilles H. M., 2002) menyatakan bahwa makin tinggi proporsi nyamuk parous, semakin lama umur nyamuk. Perkiraan umur 
populasi nyamuk $A n$. farauti di ekosistem pantai adalah 16-18 hari, sedangkan di ekosistem rawa adalah 12-14 hari. Perkiraan umur tersebut menunjukkan bahwa nyamuk An.farauti pada kedua ekosistem penelitian memiliki potensi menjadi vektor malaria. Salah satu faktor yang mempengaruhi umur populasi nyamuk Anopheles adalah kemampuan menghasilkan telur vektor tersebut. Semakin banyak nyamuk yang memiliki kemampuan bertelur maka semakin panjang usia populasi spesies tersebut. Jumlah nyamuk yang sudah pernah bertelur berbanding lurus dengan umur populasi nyamuk di alam.

C. Perilaku Mencari Darah

Perilaku nyamuk An. farauti mencari darah pada penelitian ini dibedakan berdasarkan waktu, tempat dan kesukaan terhadap sumber darah. Penelitian di ekosistem pantai menunjukkan bahwa nyamuk An. farauti paling banyak tertangkap pukul 18.00-19.00 dan terendah pukul 01.00-02.00. Hasil penelitian di ekosistem rawa juga menunjukkan bahwa spesies tersebut paling banyak tertangkap pukul 18.00-19.00, terendah pada pukul 01.00-02.00. Data tersebut menunjukkan bahwa puncak aktivitas mencari darah nyamuk An. farauti di ekosistem pantai dan rawa berlangsung pada waktu yang sama yaitu pukul 18.00-19.00 (Gambar 2).

Nyamuk Anopheles betina biasanya menghisap darah manusia untuk perkembangan telurnya dan melakukan aktivitas tersebut mulai pukul 18.00 hingga 06.00. Puncak waktu menghisap darah setiap spesies berbeda-beda tergantung kondisi lingkungannya. Penelitian di Gujarat India Tengah terhadap An. aconitus menunjukkan bahwa spesies tersebut mulai mencari darah pukul 18.00 dan mencapai puncak pada pukul 02.00 (Bhatt and Kohli, 1996). Nyamuk An. balabacencis dan An. maculatus di India dilaporkan mencari darah sepanjang malam, mulai sore hari dan paling banyak ditemukan pada pukul 21.00-24.00 ((Rao, 1961), 1961). Penelitian pada nyamuk An. barbirostris menunjukkan hal berbeda, spesies tersebut di laporkan mencari darah sepanjang malam, namun terbanyak pada pukul 22.00-23.00. Nyamuk An. maculatus juga ditemukan paling banyak mencari darah pada pukul 22.00-23.00 dan lebih banyak ditangkap diluar rumah (Munif and Yusniar, 2005).

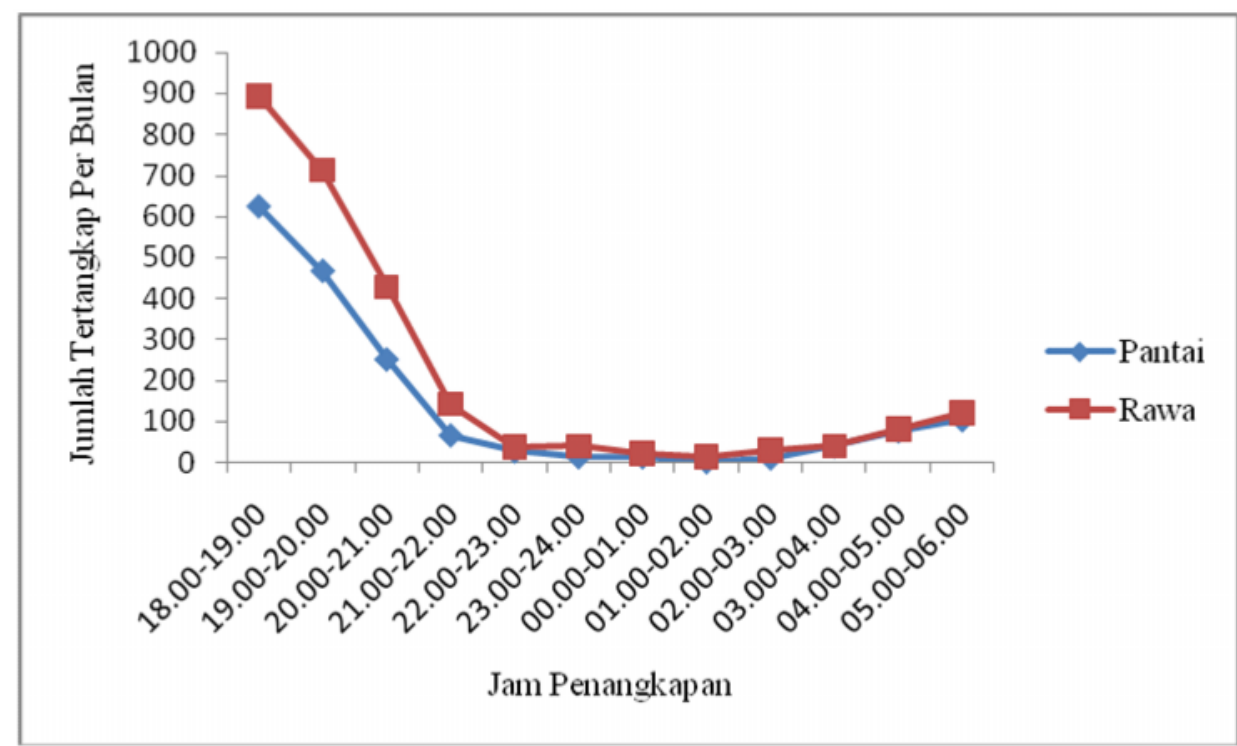

Gambar 2. Aktivitas Mencari Darah Nyamuk An. farauti di Ekosistem Pantai (Kabupaten Biak Numfor) dan Rawa (kabupaten Asmat). 
Hasil penelitian juga menunjukkan bahwa nyamuk $A n$. farauti di ekosistem pantai dan rawa lebih banyak melakukan aktifitas mencari darah di luar rumah. Penelitian terhadap beberapa spesies Anopheles di Kabupaten Pandeglang juga menunjukkan aktivitas sama. Nyamuk $A n$. annularis, An. sundaicus, An. vagus ditemukan banyak beraktivitas di luar rumah (Mardiana. et al., 2007), demikian juga An. barbirostris di Desa Lengkong Kabupaten Sukabumi (Munif and Sudomo. M., 2007).

Hasil ELISA pakan darah membuktikan bahwa nyamuk $A n$. farauti di ekosistem pantai sebagian besar bersifat zoofilik, sedangkan di ekosistem pantai bersifat antrophofilik. Data tersebut menunjukkan bahwa nyamuk An. farauti di ekosistem rawa memiliki potensi lebih besar menjadi vektor malaria di banding An. farauti ekosistem pantai. Proporsi nyamuk menghisap darah manusia akan menentukan potensi spesies tersebut sebagai vektor primer atau sekunder di daerah tersebut (Dharmawan, 1993).

Distribusi malaria ditentukan oleh berbagai faktor, diantaranya bionomi vektor seperti umur, kebiasaan mencari darah (waktu, tempat, pemilihan sumber pakan/sifat antropofilik), siklus gonotrofik, kondisi lingkungan dan kehidupan sosial masyarakat setempat. Keseluruhan faktor tersebut saling terkait dan mempengaruhi endemisitas malaria di suatu wilayah.

Secara keseluruhan terlihat bahwa terdapat perbedaan perilaku (bionomik) An. farauti di ekosistem pantai dan rawa dalam hal kepadatan, umur dan kebiasaan mencari darah, namun perbedaan perilaku tersebut tidak menjadi faktor penentu tinggi rendahnya jumlah kasus malaria pada kedua wilayah penelitian. Perbedaan perilaku nyamuk $A n$. farauti pada dua ekosistem penelitian, menyebabkan adanya perbedaan kompetensi vektor tersebut dalam menyebarkan penyakit malaria di ekosistem pantai dan rawa.

Padat populasi nyamuk $A n$. farauti di ekosistem pantai relatif lebih rendah dibanding ekosistem rawa. Padat populasi vektor di ekosistem dapat memperbesar resiko penularan, walaupun bukan faktor tunggal penentu terjadinya malaria. Nyamuk An. farauti pada kedua wilayah penelitian melakukan aktivitas mencari darah sepanjang malam dan puncak kegiatan terjadi pada waktu sama yaitu pukul 18.00-19.00. Umur populasi nyamuk An.farauti pada semua lokasi pengambilan sampel di ekosistem pantai dan rawa menjadi salah satu potensi spesies tersebut menjadi vektor efisien. Sifat antropofilik nyamuk $A n$. farauti di ekosistem rawa memperbesar kemampuan vektor tersebut dalam menyebarkan malaria.

\section{KESIMPULAN DAN SARAN}

Kepadatan, umur dan kebiasaan mencari darah nyamuk $A n$. farauti di Kabupaten Biak Numfor dan Kabupaten Asmat, menjadi faktorfaktor yang mendukung terjadinya transmisi malaria di wilayah tersebut.

Perilaku vektor bersifat lokal spesifik, sebab itu pemahaman terhadap perilaku vektor pada setiap wilayah disarankan menjadi salah satu dasar dalam setiap program pengendalian malaria.

\section{DAFTAR PUSTAKA}

Bhatt, R. M. \& Kohli, V. K. (1996) Bitting Rhytms of some Anophelines in Central Gujarat Indian J. Mal, 33180-190.

Boewono, D. T. \& Ristiyanto. (2005) Studi bioekologi vektor malaria di Kecamatan Srumbung, Kabupaten Magelang, Jawa Tengah. Bull. Penel. Kesehatan, 33(2).

Dharmawan, R. (1993) Metoda Identifikasi Spesies Kembar Nyamuk Anopheles, Sebelas Maret Univ. Press. 1-157.

Laihad, F. J. \& Gunawan, S. (1999) Malaria Di Indonesia. Dalam : Malaria, Epidemiologi, Patogenesis, Manifestasi Klinis Dan Penanganan.

Mardiana., Sukowati S. \& Wigati, R. A. (2007) Beberapa aspek perilaku nyamuk Anopheles Sundaicus di Kecamatan Sumur Kabupaten Pandeglang. Buletin Penelitian Kesehatan : 6(3): 624-630.

Munif, A. \& Sudomo. M. (2007) Bionomik Anopheles spp di daerah endemis malaria di Kecamatan Lengkong, Kabupaten Sukabumi. Buletin Penelitian Kesehatan, 35(2): 57-80.

Munif, A. \& Yusniar (2005) Tabel Kehidupan An.aconitus Sebagai Pendukung Analisis Epidemiologi Penyakit Tular Vektor. Media 
Penelitian dan Pengembangan Kesehatan, Vol XV No 4.

Najera, J. A. \& Zaim, M. (2003) Prevention and Eradication. World Health Eradication Communicable Diesease Control, Decision Making Criteria and Procedure for Judicious Use of Insecticides Malaria Vector Control. WHO Pesticide Evaluation Schme (WHOPES), WHOPES/2002. 5 Rev.1.

Rao, R. T. (1961) Vector for Malaria in India Anopheles sundaicus (Rodenwaldt) 1925. World Health Organization. 59-71.

RI, K. K. (2011) Epidemiologi Malaria di Indonesia. Direktorat Pengendalian Penyakit Bersumber Binatang. Buletin Jendela Data dan Informasi Kesehatan Triwulan 1.

Suprapto, G. (2010) Perilaku Nyamuk Anopheles Punctulatus Donitz dan Kaitannya dengan Epidemiologi Malaria di Desa Dulonpokpok Kabupaten Fakfak Provinsi Papua Barat.
Tesis. Sekolah Pascasarjana Institut Pertanian Bogor.

Taken, W. \& Knols, B. G. J. (1990) A Taxonomic and Bionomic Review of Malaria Vectors of Indonesia In Taken, W., Snellen, W.B., Verhave, J.P., Knols, B.J.G, and Atmossoedjono, S. (eds), Environmental Measures For Malaria Control in Indonesia, A Historical Review on Species Sanitation. Agriculture Wageningen. Netherlands, 2146.

Warrel, D. A. \& Gilles H. M. (2002) Essential Malariology Fourth Edition, London, New York, New Delhi.

Warrel, D. A. \& Gilles, H. M. (2002) Essential Malariology Fourth Edition, London, New York, New Delhi, Arnold. 